\title{
Mortality in Relation to The Type of Household Among Elderly People Living in a Community
}

\author{
Noriyuki Nakanishi, Ikuko Nakura, Kiyoshi Nagano, Hideo Yoneda, Toshio Takatorige, \\ Fumiaki Shinsho, and Kozo Tatara
}

\begin{abstract}
The objective of this study was to determine whether there is an association of mortality with the type of household in elderly people. A cohort of 1,352 elderly people aged 65 years and over at baseline in October 1992 was followed for 42 months. Follow-up was completed for 1,266 (93.6\%) (172 deceased and 1,094 alive). From the analysis using the Kaplan-Meier method and the log-rank test, male sex, older age group ( 75 years and over), no satisfaction with present dwelling, disability, no use of health checks, no practices of daily preventive health promotion, no participation in social activities, and no finding life worth living (no lkigai)were univariately statistically significantly related to mortality. Furthermore, elderly people living with their spouse only or living alone had higher survival rates than those living with their spouse and children or living with their children, and the curves among the four subclasses of household were significantly different. From the Cox proportional hazards model, living with a spouse only remained as an independent predictor for survival, and living alone was not an increased risk factor for mortality, controlling for sex, age, housing conditions, disability, use of health management, and psychosocial conditions.

J Epidemiol, $1998 ; 8: 65-72$.
\end{abstract}

elderly people, cohort study, mortality, type of household

Although it is still common for elderly people in Japan to live with their children or grand-children, the percentage of three-generation households among those with elderly members aged 65 years and over decreased from $54.4 \%$ in 1975 to $33.3 \%$ in $1995^{1}$. Such a drop in the ratio of the elderly living with their children or grand-children combined with the upward trend of single-person households (8.6\% in 1975 and $17.4 \%$ in 1995) and those made up of elderly couples only ( $13.1 \%$ in 1975 and $24.2 \%$ in 1995 ), has introduced a decline in long-standing family functions, such as the care of aged parents and mutual support among families. To enable sensible planning for the provision of health care services for this section of the population, an evaluation of health of elderly people living alone or elderly couples only is needed.

The World Health Organization has described elderly people living alone as an at risk group that could be targeted for specific attention ${ }^{2}$. The idea that living alone is a risk factor for morbidity and mortality of elderly people is appealing in a time of space resources and has face validity ${ }^{3 A}$. However, Iliffe et $\mathrm{al}^{5}$. have recently reported that elderly people living alone did not have an excess of morbidity compared with those living with others and did not seem to be an at risk group requiring specifically targeted assessments. In the five-year follow-up of elderly people aged 75 years and over, Jagger and Clarke ${ }^{6}$ reported that for those living alone the risk of death was $30 \%$ less than the risk of death for those living with others. Whether living alone is a risk factor for morbidity and mortality remains unclear at present. As for elderly couples, a number of previous studies have demonstrated that living with a spouse is associated with a substantial decrease in the risk of morbidity and mortality ${ }^{7-16)}$. Doherty et $\mathrm{al}^{12}{ }^{12}$. reported that the presence of a spouse is important during illness not only in the promotion of compliance with a treatment regimen but also to summon help when it is needed. Reed et $\mathrm{al}^{13 \text { ) }}$. indicated that a spouse is a key provider of social support, which has been associated strongly with health status. Whether the hypothesis conducted in western countries that living with a spouse may promote better health and contribute to improving the survival of elderly people is adaptable to Japanese elderly is necessary to be tested.

Received August 25, 1997 ; accepted September 28, 1997.

Address for correspondence : Noriyuki Nakanishi, Department of Public Health Osaka University Medical School 2-2 Yamada-oka, Suita-shi, Osaka 565, Japan. 
With the effects of potentially confounding sex, age, disability, use of health management, and psychosocial variables controlled, the present analysis was undertaken to determine whether usual home circumstances were predictive of mortality in a population of community-residing elderly people, with special reference to the type of household.

\section{METHODS}

\section{Subjects and Baseline Data}

On October 11992 when this study was started, the city of Settsu in northern Osaka Prefecture had a total population of 87,293 , of whom 6,674 were aged 65 years and older. A randomly selected sample of 1,491 people aged 65 years and older (22.3\%) from the computerized sex-age register, including 21 people in a nursing home, were visited at home by 98 welltrained district welfare commissioners for this study between 1 and 26 October 1992. Five people in the sample were found to have died, and 13 had moved from Settsu, leaving 1,473 people to be contacted; responses were obtained from 1,405, a response rate of $95.4 \%$. Reasons for non-response were: absent (15); hospitalization (25); placement in an institution (21); refusal to participate (7).

The questionnaire included items related to the following: demographic characteristics, health status as indicated by disability scores, history of health management and psychosocial conditions. The demographic characteristics covered sex, age, and home circumstances. According to home circumstances, our questionnaire asked about the total number of people in the household (including him/herself), persons whom they lived with, the type of housing, and the degree of satisfaction with present dwelling. For measuring disability, we adopted the concepts and methods developed by the Social Survey Division of the Office of Population Censuses (OPCS) ${ }^{17}$. Questionnaires are used to measure ten main areas or types of disability - locomotion, reaching and stretching, dexterity, seeing, hearing, personal care, continence, communication, behavior and intellectual functioning. Each type of disability is scored on a scale from 0 , which represents no disability, up to a maximum which differs for each item, the highest number corresponding to the most severe grade of disability. Because multiple disabilities are frequent, the OPCS survey developed an overall severity score based on the following formula using the scores for the three worst disability scores for each person: worst +0.4 (second worst) +0.3 (third worst). In our study, we also adopted this method to arrive at an 'overall disability score'. For health management, we inquired into the history of attendance for regular health checks and day-to-day preventive health practices related to diet and exercise, and into current medical treatment. For assessing psychosocial conditions, our questionnaire asked about elderly people's involvement in their social network, the presence of activities considered as particularly meaningful, and anxieties about the future. The question posed in the questionnaire is, 'Do you have Ikigai?' which could be translated directly as 'Do you have anything to live for?'. It refers to particular aspects of one's life which make it meaningful or worth living. Details of the questionnaire have been published elsewhere ${ }^{18}$ 19).

Of 1,405 people whose responses were obtained, 390 people (27.8\%) lived with their spouse and children or grand-children, $453(32.2 \%)$ lived with their children or grand-children, 355 (25.3\%) lived with their spouse only, 32 (2.3\%) lived with non-relatives, and $175(12.5 \%)$ lived alone. For analysis of this study, the type of household was grouped into four categories: living with spouse and children (including grand-children), living with children (including grand-children), living with spouse only and living alone, and people living with non-relatives were excluded from the analysis. Since general health status, a sense that life is worth living (Ikigai), and anxiety about the future used in this study were self-rated, a further 21 people, who were clinically judged as dementia by their doctors and were considered unable to answer the items of the questionnaire reliably, were excluded from the analysis. After excluding these 53 people, total of 1,352 people (384 living with their spouse and children, 442 living with their children, 353 living with their spouse only, and 173 living alone) constituted the study population.

The independent variables mentioned above were treated as categorical variables: sex (female vs male); age (younger than 75 vs equal or older); type of housing (owner occupied vs tenancy); opinion about the present dwelling (satisfied vs not satisfied); disability (no for an overall disability score of 0 vs yes for that of 0.5 and more); use of health checks (yes vs no); practices of daily preventive health promotion (yes vs no); medical treatment (no vs yes); participation in social activities (yes vs no); a sense that is worth living (Ikigai) (yes vs no); and anxiety about the future (no vs yes). As for the type of household, we created the new variables as follows; living with spouse and children (type $1=0$, type $2=0$, type $3=0$ ); living with children (type $1=1$, type $2=0$, type $3=0$ ); living with spouse only (type $1=0$, type $2=1$, type $3=0$ ); living alone (type $1=0$, type $2=0$, type $3=1$ ). All the variables were coded as 0 for no potential risk factors and 1 for potential risk factors.

\section{FOLLOW UP SURVEY}

The survey population's status as of the end of March 1996 was determined from their resident registration cards and death certificates in order to verify their eligibility and outcomes. Of the 1,352 subjects enrolled in this study, the follow-up could be completed for only 1,266 (172 deceased and 1,094 alive) because 86 had moved from Settsu by the time of the followup. 


\section{STATISTICAL METHODS}

The statistical difference of the characteristics of elderly people at enrollment in relation to the four types of household was examined by the chi-square test. For survival analyses, the survival times were calculated by using the date of enrollment and the date of death or the date of follow-up (end of March 1996) or the date of last registration. Those who had moved from Settsu city during the follow-up period have censored survival times, and those members of the cohort who were living in the city of Settsu at end of the follow-up and who were still alive also have censored survival times. The method of KaplanMeier ${ }^{20)}$ was used to estimate the cumulative survival of the elderly according to the characteristics found from baseline data, and the log-rank test was used to assess the significance of the unadjusted difference among survival curves. Multivariate analysis was performed by the Cox proportional hazards model ${ }^{211}$ to identify subsets of independent prognostic factors for mortality, and hazard ratios (HRs) and $95 \%$ confidence interval $(\mathrm{CI})$ were calculated. A HR of 1 indicates that there is no difference between the subgroups: a HR $>1(<1)$ indicates that a person in the designated "risk" subgroups is more (less) likely to die than a person in the designated baseline subgroup, given that all other determinants of survival are the same.

For all analyses, $\mathrm{p}$-values less than 0.05 was considered significant. Data analysis was performed with the SPSS/PC statistical package.

\section{RESULTS}

\section{Characteristics at Enrollment}

Table 1 shows the characteristics of elderly people according to the type of household. More than four fifths were women among the subjects living with their children or living alone, and more than a half of those living with their children were aged 75 years and over. Nearly three fifths of those living alone lived in the rented house. The proportion of those who reported to be unsatisfied with the present dwelling did not differ significantly among the four types of household. The proportion of those with disability was higher among those living with their children than among those living with their spouse

Table 1. Characteristics of the elderly in relation to the type of household. (values number of elderly (\% of group))

\begin{tabular}{|c|c|c|c|c|c|c|c|}
\hline \multirow[b]{2}{*}{ Characteristics } & \multirow[b]{2}{*}{ Subclass } & \multicolumn{4}{|c|}{ Type of household } & \multirow[b]{2}{*}{$\mathrm{p}$} & \multirow[b]{2}{*}{ value * } \\
\hline & & $\begin{array}{r}\text { Living with } \\
\text { spouse and children } \\
(n=384)\end{array}$ & $\begin{array}{l}\text { Living with } \\
\text { children } \\
(n=442)\end{array}$ & $\begin{array}{l}\text { Living with } \\
\text { spouse only } \\
(n=353)\end{array}$ & Living alone & & \\
\hline \multirow[t]{2}{*}{ Sex } & Male & $221(57.6)$ & $80(18.1)$ & $214(60.6)$ & $31(17.9)$ & & $<.001$ \\
\hline & Female & $163(42.4)$ & $362(81.9)$ & $139(39.4)$ & $142(82.1)$ & & \\
\hline \multirow[t]{2}{*}{ Age } & $\geq 75$ years & $115(29.9)$ & $243(55.0)$ & $88(24.9)$ & $68(39.3)$ & & $<.001$ \\
\hline & $65-74$ years & $269(70.1)$ & $199(45.0)$ & $265(75.1)$ & $105(60.7)$ & & \\
\hline \multirow[t]{2}{*}{ Type of housing } & Tenancy & $45(11.7)$ & $96(21.7)$ & $93(26.3)$ & $100(57.8)$ & & $<.001$ \\
\hline & Owner occupied & $339(88.3)$ & $346(78.3)$ & $260(73.7)$ & $73(42.2)$ & & \\
\hline \multirow[t]{2}{*}{ Satisfaction with present dwelling } & No & $184(47.9)$ & $202(45.7)$ & $143(40.5)$ & $75(43.4)$ & & .219 \\
\hline & Yes & $200(52.1)$ & $240(54.3)$ & $210(59.5)$ & $98(56.6)$ & & \\
\hline \multirow[t]{2}{*}{ Disability† } & Yes & $208(55.2)$ & $313(72.6)$ & $181(51.6)$ & $98(57.6)$ & & $<.001$ \\
\hline & No & $169(44.8)$ & $118(27.4)$ & $170(48.4)$ & $72(42.4)$ & & \\
\hline \multirow[t]{2}{*}{ Use of health checks } & No & $91(23.7)$ & $132(29.9)$ & $58(16.4)$ & $47(27.2)$ & & $<.001$ \\
\hline & Yes & $293(76.3)$ & $310(70.1)$ & $295(83.6)$ & $126(72.8)$ & & \\
\hline \multirow[t]{2}{*}{ Daily preventive health practices } & No & $262(68.2)$ & $313(70.8)$ & $202(57.2)$ & $104(60.1)$ & & $<.001$ \\
\hline & Yes & $122(31.8)$ & $129(29.2)$ & $151(42.8)$ & $69(39.9)$ & & \\
\hline \multirow[t]{2}{*}{ Medical treatment } & Yes & $286(74.5)$ & $337(76.2)$ & $260(73.7)$ & $130(75.1)$ & & .860 \\
\hline & No & $98(25.5)$ & $105(23.8)$ & $93(26.3)$ & $43(24.9)$ & & \\
\hline \multirow[t]{2}{*}{ Participation in social activity } & No & $212(55.2)$ & $306(69.2)$ & $178(50.4)$ & $105(60.7)$ & & $<.001$ \\
\hline & Yes & $172(44.8)$ & $136(30.8)$ & $175(49.6)$ & $68(39.3)$ & & \\
\hline \multirow[t]{2}{*}{ Life worth living (Ikigai) } & No & $63(16.4)$ & 85 (19.2) & $45(12.7)$ & $33(19.1)$ & & .081 \\
\hline & Yes & $321(83.6)$ & $357(80.8)$ & $308(87.3)$ & $140(80.9)$ & & \\
\hline \multirow[t]{2}{*}{ Anxiety about the future } & Yes & $261(68.0)$ & $301(68.1)$ & $281(79.6)$ & $126(72.8)$ & & $<.001$ \\
\hline & No & $123(32.0)$ & $141(31.9)$ & $72(20.4)$ & $47(27.2)$ & & \\
\hline
\end{tabular}

* Chi-square test.

$\dagger$ Complete data for measuring an overall severity score were not available for 23 people. 
and children, their spouse only or living alone. The percentages of those who had been receiving health checks or had paid particular attention to their dietary and exercise regimens were the highest among those living with their spouse only and were the lowest among those living with their children. There were no significant differences among the four types of household in the proportion of those with medical treatment. As for psychosocial conditions, the proportion of those who took part in social activities was the highest among those living with their spouse only and was the second highest among those living with their spouse and children. The proportion of those who found life worth living was slightly higher among those living with their spouse only, but did not differ significantly among the four types of household. The proportion of those who experienced anxiety about the future was the highest among those living with their spouse only, and was the second highest among those living alone.

\section{UNIVARIATE ANALYSIS FOR SURVIVAL}

Table 2 shows the estimated survival rates of elderly people during 42 months by Kaplan-Meier method. The estimated $42-$ month survival rate for women was higher than that for men ( $89.5 \%$ vs $82.7 \%)$, and the curves between both sexes were significantly different by the log-rank test. The estimated survival rates for those aged 65-74 years and for those aged 75 years and over were $91.6 \%$ and $78.8 \%$, respectively. This difference achieved a statistical significance by the log-rank test. The estimated survival rate according to the type of household was the highest among those living with their spouse only $(92.0 \%)$ and was the second highest among those living alone $(89.2 \%)$, and the curves among the four subclasses of household were significantly different. The estimated survival rates for those who lived in the rented house and for those who had their own house showed the least difference $(88.2 \%$ vs $86.3 \%)$ in the variables shown in Table 2, and this difference did not achieve a statistical significance by the log-rank test. The estimated survival rate for those who reported to be satisfied with the present dwelling was higher than that for those unsatisfied with $(89.1 \%$ vs $83.8 \%)$, and the curves between two groups were significantly different by the log-rank test. The estimated survival rate for those with disability was lower than that for

Table 2. Survival rates of the elderly over 42 months by Kaplan-Meier method.

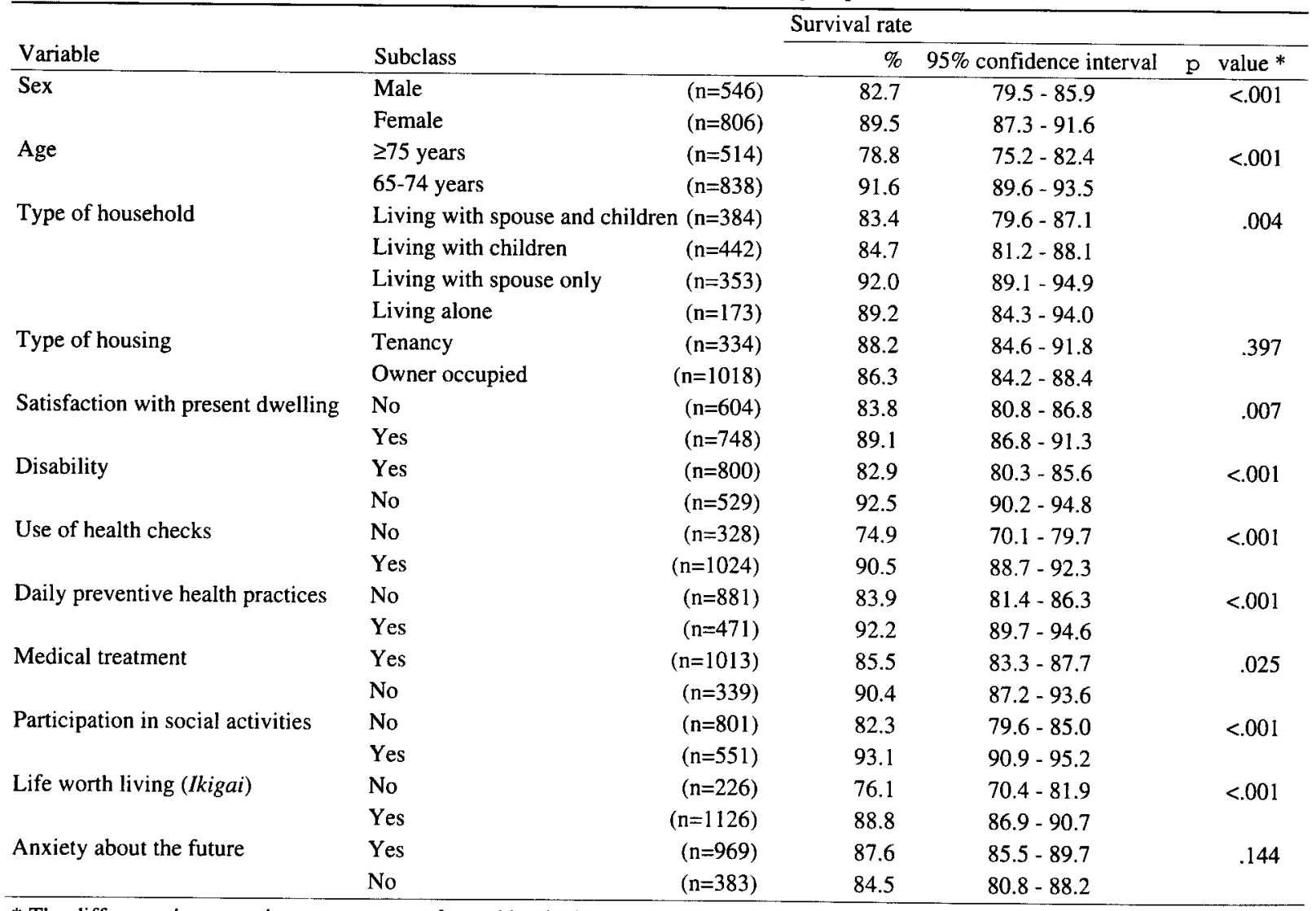

* The difference between the curves was performed by the log-rank test. 
Table 3. Hazard ratios for mortality over 42 months by Cox proportional hazards model.

\begin{tabular}{lrcr}
\hline Risk factor * & Hazard ratio & 95\% confidence interval & $\mathrm{p}$ value * \\
\hline Male sex & 2.27 & $1.61-3.19$ & $<.001$ \\
Age $\begin{array}{l}\text { Type of household } \neq \\
\quad \text { Type 1 }\end{array}$ & 1.40 & $1.24-1.59$ & $<.001$ \\
$\quad$ & & & \\
$\quad$ Type 2 & 0.73 & $0.49-1.08$ & .117 \\
$\quad$ Type 3 & 0.60 & $0.38-0.95$ & .031 \\
Type of housing, tenancy & 0.82 & $0.46-1.46$ & .498 \\
No satisfaction with present dwelling & 0.92 & $0.62-1.36$ & .673 \\
Overall disability score $\dagger$ & 1.27 & $0.93-1.75$ & .137 \\
No use of health checks & 1.30 & $1.11-1.51$ & $<.001$ \\
No daily preventive health practices & 1.99 & $1.42-2.78$ & $<.001$ \\
Medical treatment & 1.74 & $1.18-2.57$ & .006 \\
No participation in social activities & 1.36 & $0.90-2.04$ & .142 \\
No life worth living (Ikigai) & 1.52 & $1.01-2.31$ & .047 \\
Anxiety about the future & 1.17 & $0.82-1.68$ & .387 \\
\hline
\end{tabular}

* Risk factors are dichotomous except age and overall disability score.

†Age and overall disability score are exact values. Units are change in 5 years for age and 5 points change for overall disability score.

$\ddagger$ Living with spouse and children (type $1=0$, type $2=0$, type $3=0$ ), living with children (typel $=1$, type $2=0$, type $3=0$ ), living with spouse only (type $1=0$, type $2=1$, type $3=0$ ), living alone (type $1=0$, type $2=0$, type $3=1$ ).

those without $(82.9 \%$ vs $92.5 \%)$, and this difference achieved a statistical significance by the log-rank test. According to health management, the estimated survival rates for those who had been receiving health checks or had paid particular attention to their dietary and exercise regimens were $90.5 \%$ and $92.2 \%$, respectively, while those for who had not were $74.9 \%$ and $83.9 \%$, respectively. These differences were both statistically significant by the log-rank test. The estimated survival rate for those with medical treatment was lower than that for those without ( $85.5 \%$ vs $90.4 \%$ ), and the curves between two groups achieved a statistical significance by the log-rank test. As for psychosocial conditions, the estimated survival rates for those who took part in social activities or found life worth living were $93.1 \%$ and $88.8 \%$, respectively, while those for who did not were $82.3 \%$ and $76.1 \%$, respectively. These differences were both statistically significant by the log-rank test. The estimated survival rate for those who experienced anxiety about the future was slightly higher than that for those who did not ( $87.6 \%$ vs $84.5 \%$ ), but there was no significant difference by the log-rank test.

\section{MULTIVARIATE ANALYSIS FOR SURVIVAL}

The factors evaluated for their predictive value were assessed for their relationship to mortality by the Cox proportional hazards model (Table 3). Statistically significant factors associated with mortality were: male sex $(H R=2.27,95 \%$
$\mathrm{CI}=1.61-3.19$ ), age (an increase in 5 years; $\mathrm{HR}=1.40,95 \%$ $\mathrm{CI}=1.24-1.59$ ), overall disability score (an increase in 5 points; $\mathrm{HR}=1.30,95 \% \mathrm{CI}=1.11-1.51$ ), no use of health checks ( $\mathrm{HR}=1.99,95 \% \mathrm{CI}=1.42-2.78$ ), no use of daily preventive health practices $(\mathrm{HR}=1.74,95 \% \mathrm{CI}=1.18-2.57)$, and no participation in social activities $(\mathrm{HR}=1.52,95 \% \mathrm{CI}=1.01-2.31)$. No satisfaction with present dwelling, medical treatment, and no life worth living (Ikigai) showed the HRs greater than 1, but were not statistically significant. On the other hand, living with spouse only represented as the variable of type 2 remained as an independent predictor for survival ( $H R=0.60,95 \%$ $\mathrm{CI}=0.38-0.95$ ). The HRs for type 2 (living with children), type 3 (living alone), tenancy housing, and anxiety about the future were less than 1 , but were not statistically significant.

\section{DISCUSSION}

A number of previous studies have already demonstrated both theoretical bases and empirical evidence for causal links existing between some indicators and health in elderly people $4,6,13,18,19,22-28)$. Male sex, older age, subject sense of well-being, disability, satisfaction with life, social support, and sociability are stable predictive factors for mortality. Our study also showed close relations between male sex, older age, health status as indicated by disability scores and the risk of mortality in a community-residing elderly people. As for psychosocial conditions evaluated in this study, no participation in social activi- 
ties and the lack of a sense that is worth living (Ikigai) were significantly related to the mortality of the elderly by univariate analysis, and no participation in social activities remained as a significant predictive factor after multivariate analysis. These results provide some evidence that comparatively less decline in general health and participation in social activities reflect an active physiological and psychological profile and a better adaptation to the environment and contribute to reducing the mortality of elderly people. Comparing the degrees of social activities by the elderly with those in other countries, it is observed that elderly people in Japan are generally less active than those in the European countries and in the USA ${ }^{29)}$. Japanese people, especially men, have a marked tendency to attach their sense that is worth living (Ikigai) to their work, and retirement from work often has a serious impact on their sense of self-worth in old age. Considering that no participation in social activities and no finding life worth living (Ikigai) were closely related to the mortality of the elderly, it is necessary for society to let them make the most of their abilities and creativity and to restructure itself to positively receive the social activities of elderly people.

As for health management, the positive relationship between the whole spectrum of physical health and actual daily good health habits has been demonstrated ${ }^{30,31)}$. A randomized trial in Copenhagen ${ }^{32)}$ suggested that health checks at 3 month intervals resulted in reductions in mortality and lengths of hospital stay. A study in south Wales ${ }^{33}$ also showed an apparent reduction in mortality in one of two centers and other studies ${ }^{34,35)}$ have shown improvements in morale. Nakanishi et al ${ }^{18,19}$. recently reported independent inverse associations between daily preventive health practices and the use of health checks and the subsequent occurrence of disability and mortality in old age. But large randomized controlled trials in the USA and UK have cast doubts on the benefits of screening and health checks, and they have come under critical scrutiny ${ }^{36,37}$. In this study survival analysis showed that the estimated survival rate for the subjects who had been receiving health checks or had paid particular attention to their dietary and exercise regimens were significantly higher than that for those who had not. From the multivariate analysis, no use of health checks and no practices of daily preventive health promotion remained as statistically significant factors associated with mortality, controlling for other indicators such as sex, age, medical treatment, disability, and psychosocial conditions, which have already been identified in previous epidemiological research ${ }^{4,} 6,13,18,19,22-28$ ). These results suggest that positive behavioral pattern to health maintenance and promotion may contribute to better health in old age and to reducing the mortality of the elderly. The factors that promote the development and maintenance of health management remain to be explored, but healthy psychosocial conditions may motivate the adoption of preventive health practices and the use of health checks ${ }^{18}{ }_{19}$ ).
As for mortality in relation to usual home circumstances, elderly people living alone or living with their spouse only had higher survival rates than those living with their spouse and children or living with their children through the end of 42 months of observation. The survival rate for those who reported to be satisfied with the present dwelling was significantly higher than that for those unsatisfied with. By the multivariate analysis, living with spouse only remained as the positive predictive factor for survival, controlling for other indicators. These results suggest that the survival of elderly people is associated with home circumstances. Living with a spouse may be associated with a substantial decrease in the risk of mortality in elderly people, and elderly people living alone are not a group at risk in regard to mortality as previous studies from western countries have indicated ${ }^{6-13,15,16)}$.

When examining the causes for these results, at least three factors should be taken into consideration. One is that elderly people living their spouse only or living alone had healthier status as indicated by disability scores than those living their children. The proportions of younger age group (65-74 years) and female sex were the highest among those living with their spouse only and among those living alone, respectively. Behavior to health management, participation in social activities, and life worth living (Ikigai) were the most active among those living their spouse only. Thus, our results may reflect interactions between health, psychosocial conditions, home circumstances, and longevity, although our main interest is in the effect of type of household on mortality. The second is that we could not assess the socio-economic circumstances of participants, in particular education level, occupation, and economic status, although they may well be associated with mortality, with the psychosocial conditions, and with the likelihood of health management ${ }^{11,14,16,38}$. The third is that the use of mortality data is not appropriate to know whether the type of household influences incidence of disease, recovery, or case fatality. Further investigation is needed to clarify whether the type of household is simply associated with survival or contributes to or is responsible for survival of elderly people, together with some idea of their influence on the course of disease, from the development of risk factors through incidence of disease to the outcome of the disease process.

In conclusion, older people living their spouse only showed a substantial decrease in the risk of mortality, and elderly people living alone did not have an excess of mortality. However, those living with their spouse only or living alone experienced more anxiety about the future, so awareness of those with these conditions may encourage not only all agencies, friends and neighbors to co-operate in bringing individuals' needs to the attention of those who can offer help but also care staff to provide appropriate community health services, especially with a point of contact in case of emergency. 


\section{ACKNOWLEDGMENT}

The authors would like to thank two referees for their helpful comments. This study was supported in part by Grand-in-Aid for Scientific Research 08670426 from the Ministry of Education, Science, and Culture

\section{REFERENCES}

1. Health and Welfare Statistics Association. Kokumin eisei no doko 1996 (Trends in the nation's health, 1996). Tokyo: Kosei no shihyo, 1996 (in Japanese).

2. World Health Organisation. Prevention of mental disorders in the elderly. Copenhagen: WHO, 1977.

3. Royal College of General Practitioners. Care of old people: a framework for progress. London: RCGP, 1990. (Occasional paper 45.)

4. Hanson BS, Isacsson S-O, Janzon L, Lindell S-E. Social network and social support influence mortality in elderly men. Am J Epidemiol 1989;130:100-111.

5. Iliffe S, Tai SS, Haines A, et al. Are elderly people living alone an at risk group? Br Med J 1992;305:1001-1004.

6. Jagger C, Clarke M. Mortality risks in the elderly: fiveyear follow-up of a total population. In J Epidemiol 1988;17:111-114.

7. Rees WD, Lutkins SG. Mortality of bereavement. $\mathrm{Br}$ Med J 1967;4:13-16.

8. Parkes CM, Benjamin B, Fitzgerald RG. Broken heart: a statistical study of increased mortality among widowers. Br Med J 1969;1:740-743.

9. Jacobs $S$. An epidemiological review of the mortality of bereavement. Psychosom Med 1977;39:344-357.

10. Somers AR. Marital status, health, and use of health services: an old relationship revisited. JAMA 1979;241:1818-1822.

11. Koskenvuo M, Kaprio J, Kesäniemi A, Sarna S. Differences in mortality from ischemic heart disease by marital status and social class. J Chron Dis 1980;33:95106.

12. Doherty WJ, Schrott HG, Metcalf L, Iasiello-Vailas L. Effect of spouse support and health beliefs on medication adherence. J Fam Practice 1983;5:837-841.

13. Reed D, McGee D, Yano K, Feinleib M. Social networks and coronary heart disease among Japanese men in Hawaii. Am J Epidemiol 1983; 117:384-396.

14. Taylor RC, Ford EG. The elderly at risk: a critical examination of commonly identified risk groups. J R Coll Gen Pract 1983;33:699-705.

15. Suarez L, Barrett-Connor E. Is an educated wife hazardous to your health? Am J Epidemiol 1984;119:244249.

16. Malcolm JA, Dobson AJ. Marriage is associated with a lower risk of ischaemic heart disease in men. Med J Aust 1989;151:185-188.

17. Martin J, Meltzer H, Elliot D. The prevalence of disability among adults. OPCS surveys of disability in Great Britain, Report 1, London: HMSO, 1988.

18. Nakanishi N, Tatara K, Takashima Y, et al. The association of health management with the health of elderly people. Age Ageing 1995;24:334-340.

19. Nakanishi N, Tatara K, Nakajima K, et al. Mortality in relation to disabilities, health management and psychosocial conditions among the community-residing elderly people. Jpn J Public Health 1997;44:89-101 (in Japanese).

20. Kaplan EL, Meier P. Nonparametric estimation from incomplete observations. J Am Stat Assoc 1958;53:457481.

21. Cox DR. Regression models and life-tables. J R Stat Soc [B] 1972;34:187-200.

22. Libow LS. Interaction of medical, biologic and behavioral factors on ageing adaptation and survival: an 11year longitudinal study. Geriatrics 1974;29:75-88.

23. Warren MD, Knight R. Mortality in relation to the functional capacities of people with disabilities living at home. J Epidemiol Community Health 1982;36:220-223.

24. Mossey JM, Shapiro E. Self-rated health: a predictor of mortality among the elderly. Am J Public Health 1982;72:800-809.

25. Berkman LF. Social networks, support and health: taking the next step forward. Am J Epidemiol 1986;123:559562.

26. House JS, Landis KR, Umberson D. Social relationships and health. Science 1988;241:540-545.

27. Grand A, Grosclaude P, Bocquet H, Pous J, Albarede JL. Disability, psychosocial factors and mortality among the elderly in a rural French population. J Clin Epidemiol 1990;43:773-782.

28. Sugisawa H, Liang J, Liu X. Social networks, social support, and mortality among older people in Japan. J Gerontol Soc Sci 1994;49:S3-13.

29. Office of Measures for the Elderly. Roujin no seikatsu to ishiki ni kansuru kokusai hikaku chosa (An international comparative survey of life and awareness of the elderly). Tokyo: General Affairs Agency 1991 (in Japanese).

30. Belloc N, Breslow L. Relationship of physical health status and health practice. Prev Med 1972;1:409-421.

31. Breslow L. Prospects for improving health through reducing risk factors. Prev Med, 1978;7:449-458.

32. Hendriksen C, Lund E, Stromgard E: Consequences of assessment and intervention among elderly people: a three year randomised controlled trial. Br Med J 1984;298:663-668.

33. Vetter NJ, Jones DA, Victor CR. Effects of health visitors 
working with elderly patients in general practice: a randomised controlled trial. Br Med J 1984;288:369-372.

34. Tulloch AJ, Moore V. A randomized controlled trial of geriatric screening and surveillance in general practice. $\mathrm{J}$ R Coll Gen Pract 1979;29:733-742

35. McEwan RT, Davison N, Forster DP, Pearson P. Screening elderly people in primary care: a randomized controlled trial. Br J Gen Pract 1990;40:94-97.
36. Roworth MA. Screening in the elderly. Public Health 1989;103:377-383.

37. Harris A. Health checks for people over 75: the doubts persist. Br Med J 1992;305:599-600.

38. Dobson AJ, Gibberd RW, Leeder SR, O'Connell DL. Occupational differences in ischemic heart disease mortality and risk factors in Australia. Am J Epidemiol 1985;122:283-290. 